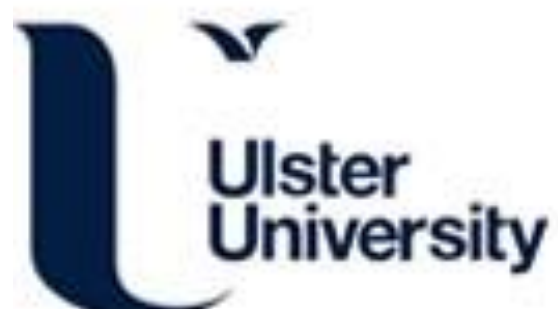

\section{Seeing for themselves - healthcare professionals' views about the presence of family members during brainstem death testing}

Doran, M., \& Black, P. (2017). Seeing for themselves - healthcare professionals' views about the presence of family members during brainstem death testing. Journal of Clinical Nursing, 26(11-12), 1597-1607. https://doi.org/10.1111/jocn.13488

Link to publication record in Ulster University Research Portal

Published in:

Journal of Clinical Nursing

Publication Status:

Published (in print/issue): 30/06/2017

DOI:

10.1111/jocn.13488

Document Version

Author Accepted version

\section{General rights}

Copyright for the publications made accessible via Ulster University's Research Portal is retained by the author(s) and / or other copyright owners and it is a condition of accessing these publications that users recognise and abide by the legal requirements associated with these rights.

\section{Take down policy}

The Research Portal is Ulster University's institutional repository that provides access to Ulster's research outputs. Every effort has been made to ensure that content in the Research Portal does not infringe any person's rights, or applicable UK laws. If you discover content in the Research Portal that you believe breaches copyright or violates any law, please contact pure-support@ulster.ac.uk. 
Received Date : 22-Mar-2016

Revised Date : 06-Jun-2016

Accepted Date : 28-Jul-2016

Article type : Original Article

Title: Seeing for themselves - healthcare professionals views about the presence of family members during brainstem death testing

\section{Author Details:}

DORAN Majella, MSc in Nursing,

BLACK Pauline, PhD, Lecturer in Nursing, School of Nursing, Ulster University, Northland Road, Londonderry, Co. Londonderry, BT48 7JL, Northern Ireland

\section{Contact Details:}

Majella Doran

Clinical Education Centre

Altnagelvin Hospital

Glenshane Road

Waterside

Londonderry

BT47 6SB

N. Ireland

Tel: (Work) 02895361200 (3) (Mobile) 07775854593

Email: majella.doran @cec.hscni.net

Funding: This research project was supported by a grant from The Band Trust via the Florence Nightingale Foundation.

\section{TITLE PAGE}

Title: Seeing for themselves - healthcare professionals views about the presence of family members during brainstem death testing

This article has been accepted for publication and undergone full peer review but has not been through the copyediting, typesetting, pagination and proofreading process, which may lead to differences between this version and the Version of Record. Please cite this article as doi: $10.1111 /$ jocn. 13488

This article is protected by copyright. All rights reserved. 


\section{Author Details:}

Funding: This research project was supported by a grant from The Band Trust via the Florence Nightingale Foundation.

\section{ABSTRACT}

Aims and objectives: This paper provides an insight into the views of healthcare professionals on the presence of family members during brainstem death testing.

Background: Brainstem death (BSD) presents families with a paradoxical death that can be difficult to define. International research suggests families should be given the choice to be present at BSD testing, yet it appears few units offer families the choice to be present and little attention has been paid to developing practice to enable effective facilitation of choice.

Design: A qualitative, exploratory design was adopted to understand the perceptions of healthcare professionals. Individual semi-structured interviews were audio-taped and carried out over two months.

Methods: A purposive sample of 10 nurses and 10 doctors from two tertiary intensive care units in the United Kingdom were interviewed and transcripts were analysed using content analysis to identify emergent categories and themes.

Results: Healthcare professionals indicated different perceptions of death in the context of catastrophic brainstem injury. The majority of participants favoured offering families the choice to be present while acknowledging the influence of organisation culture. Identified benefits included acceptance, closure and better 
understanding. Suggested challenges involved the assumption of trauma or disruption and sense of obligation for families to accept if choice was offered. Key issues involved improving knowledge and communication skills in order to individually tailor support for families involved.

Conclusions: If families are to be offered the choice of witnessing BSD testing, considering that needs and conventions will differ according to global cultural backgrounds, then key needs must be met to ensure that effective care and support is provided to families and clinicians.

Relevance to clinical practice: A proactive approach to facilitating family choice to be present at testing requires the development of guidelines that accommodate cultural and professional variations to provide excellence in end-of-life care.

\section{Summary box}

What does this paper contribute to the wider global clinical community?

- An insight into the complexity of understanding death in the context of brainstem death among healthcare professionals, their views on offering families the choice to be present during testing and the perceived benefits and concerns about the process of facilitating family presence.

- A proactive approach to facilitating family choice to be present during brainstem death tests requires the development of guidelines that take into account global cultural and professional variations to provide excellence in end-of-life care. Education programmes need to focus on improving the knowledge and communication skills of healthcare professionals to ensure 
that effective care and support is provided to families who choose to be present during brainstem death tests.

- Further research is needed to assess the effect of guidance and changes in clinical practice to identify the impact of family presence on the experience of brainstem death tests and end-of-life care.

Key words: nurses, nursing, intensive care, critical care, brainstem death, brainstem death testing, choice, families, end-of-life care

\section{SEEING FOR THEMSELVES - HEALTHCARE PROFESSIONALS VIEWS ABOUT THE PRESENCE OF FAMILY MEMBERS DURING BRAINSTEM DEATH TESTING}

\section{INTRODUCTION}

Intensive care units (ICUs) are part of the health infrastructure across the developed world. Within the remit of these units is the need to determine brainstem function for some patients admitted as a result of acute traumatic brain injury (TBI). TBI can result in significant death and disability across all societies and, in particular, among people under the age of forty (Maas et al. 2008). As the concept of family-centred care evolves so also does the need to consider the place of family members during these procedures.

The conventional concept of death is an absence of pulse and breathing however, brainstem death (BSD) is more complex to define. Brain death (BD) is evident in the absence of all brain function demonstrated by profound coma, apnoea and absence 
of brainstem reflexes (Machado 2010). The brain death criteria proposed by the Conference of Medical Royal Colleges in 1976, has been integrated into law for the diagnosis of death in England and Northern Ireland (AOMRC 2008). Current European practice is based on the concept of BSD where the diagnosis is clinical and does not entail the cessation of all neurological activity (AOMRC 2008). The cause of the neurological catastrophe leading to BSD must be irreversible in the absence of factors that may mimic BSD or confound examination (Machado 2010, Nathan \& Greer 2006). Once these criteria are met all brainstem reflexes must be absent before BSD can be diagnosed (Table 1). These criteria are recognised internationally and have, in general, been incorporated into relevant guidance worldwide (Canadian Blood Services \& WHO 2012).

This criterion for death presents families with a paradox in which the ventilated patient is warm, well-perfused and appears alive (Doran 2004). This blurring of life and death results in cognitive dissonance, an emotional state which results when two simultaneously held cognitions are inconsistent (Frid et al. 2007, Long \& AddingtonHall 2008). International evidence from research studies in Canada (MacDonald 2012), Poland (Kubler et al. 2009), Hong Kong (Leung et al. 2009, Fung et al. 2008) and the UK (Ronayne 2009, Haddow 2004), suggests there is a lack of acceptance amongst families, healthcare professionals and academics that BSD is equivalent to death. This evidence, incorporated into discussion and review across Canada (Joffe 2010), America (Bernat 2009, Shewmon 2009) and Europe (Karakatsanis 2008, Reid 2013) indicates the degree of professional interest in providing effective care to the patient and family in the context of brain stem death. 


\section{BACKGROUND}

Findings from studies carried out in America (Twail et al. 2014), the Netherlands (Kompanje et al. 2012) and the UK (Ormrod et al. 2005) suggest that families should be given the choice to be present at BSD testing. Bell et al. (2004) reported that from a sample of 113 consultant members of the Neuroanaesthesia society of Great Britain and Ireland, 22\% indicated they would allow families to observe the tests if asked and Dean and Booth (2009) reported that from a sample of 48 ICUs in the UK, 21 units allowed relatives to observe BSD testing but only 6 of these ICUs routinely invited relatives to be present. Eleven of the 21 units allowed relatives to watch if they asked and four permitted family to observe to improve their understanding of BSD.

It is generally accepted individuals have the capacity to choose and value choice over things that happen in their lives, with choice being perceived as a human right (Keith-Lucas 2010, Duss-Otterström 2011). The opportunity to make a choice results in volitional action. According to Ryan and Deci (2006), volitional action can be preceded by a state of readiness and psychological preparation that supports the choice to act. Giving families' choice may help them gain a sense of control in an uncontrollable situation. Relatives may gain confirmation of death, reduced risk of psycho-emotional harm and have a better chance of working through the grieving process (Omrod et al. 2005, Kompanje et al. 2012).

It appears relatives would like the freedom to make choices about being present with their loved one during difficult situations (Omrod et al. 2005). Evidence extrapolated from witnessed cardiopulmonary resuscitation (CPR), which is more sudden than the 
controlled procedure of BSD testing, suggests relatives do not find witnessing resuscitation either traumatising or distressing compared with the mental anguish of waiting in the relatives room (Leske \& Brasel, 2010). By offering families a choice, it is possible they will gain a sense of closure comparable to those relatives who witness CPR (Fullbrook et al. 2005).

If the choice to witness BSD testing is to be routinely offered to families as integral to family-focused care, more research is needed to explore the views and perceptions of the health care professionals who would facilitate it. It is important to gauge their readiness to offer the choice to families and to identify factors that would influence support and delivery of choice in practice. This is essential if the choice to witness BSD testing is to become a reality for families who wish to be present.

\section{Aim}

The aim of the study was to explore the views of healthcare professionals on offering families the choice to be present during BSD testing.

The objectives were to:

1. Explore the perceptions of healthcare professionals about what constitutes death and their understanding and acceptance of the concept of BSD.

2. Explore the views of healthcare professionals on family members being present at BSD testing.

3. Explore the benefits and challenges associated with the presence of family members during BSD testing from the perspective of healthcare professionals. 
4. Gain an insight into what education or support healthcare professionals feel they would need to facilitate the presence of families.

5. Explore how healthcare professionals feel family members' needs could be best met if they did choose to be present at BSD testing.

\section{METHODS}

\section{Design}

A qualitative approach using in-depth interviews was chosen as the most appropriate design. The views of healthcare professionals can be moulded by their experiences and, consequently, influence their practice. Qualitative research is a means to understand these perceptions and the resultant actions of participants (Parahoo 2014). The focus is exploratory and the intention is to understand the perspectives of the participants and to describe their responses to deepen an understanding of key issues that need to be considered in order to provide family-centred care during BSD testing.

\section{Sample/Participants}

A purposive sample $(n=20)$ of 10 nurses and 10 doctors who met the following inclusion criteria (Table 2) were recruited from two tertiary ICUs in a region of the United Kingdom:

- Registered nurses or doctors with a minimum of 5 years' experience of working in ICU.

- Experience of caring for people who have undergone BSD testing and their families. 
Health care professionals who had personal experience of bereavement as a result of BSD within the last 6 months were excluded. This was to protect those who may have valuable insights to share but may not be emotionally ready to discuss their views and who may, in time, view things differently. Potential participants were identified by the unit managers and provided with written information about the study. If they were willing to participate, they contacted the researcher to arrange a convenient time to be interviewed.

\section{Data collection}

Individual semi-structured interviews, lasting approximately one hour were conducted in the two study sites during August-September 2013. Open-ended questions were developed from key issues identified in the literature and an interview schedule was developed. The questions and prompts included are presented in

Table 3. A pilot study was undertaken, involving 1 nurse and 1 doctor, to test the method, timing of the interviews and appropriateness of the questions; no changes were required for the main study. Each interview was audio-recorded and transcribed verbatim prior to analysis with notes written immediately after each interview to capture salient points while fresh in the researcher's mind (Flick 2014).

\section{Ethical considerations}

Ethical approval was granted by the University Ethics Committee and the Research Governance Committees of the two participating healthcare settings. Participants gave written informed consent prior to the start of their interview. To ensure confidentiality each audio taped interview and transcript was coded. As the topic of the study was a sensitive one, the researcher negotiated access to services within the study settings so that any participants who may have become distressed could 
be offered support. This was, however, not required during the data collection process.

\section{Data analysis}

The study produced rich descriptive data that were systematically analysed using the method developed by Newell and Burnard (2006). Recommended for interviews recorded and transcribed in full, this method allowed categories to emerge as a result of listening and re-reading. From further coding and refinement of similar categories, the resultant themes emerged. During the 18th interview, it became clear that no new themes were emerging. Analysis of two further transcripts confirmed that data saturation had been reached.

\section{Rigour}

The trustworthiness of the study was ensured by following criteria developed by Lincoln and Guba (1985). Credibility and dependability were achieved through a sound rationale for decisions in the research process and development of researcher reflexivity where the values of the researcher as a nurse with experience of caring in the context of BSD were identified and set aside to ensure the views and perceptions of participants were truly represented.

Regular meetings between the researcher and her university supervisor facilitated the processes of peer review and confirmability as the data were analysed. This ensured data verification was objective and thorough. Consideration was given to presentation of findings in a manner that facilitated transferability or applicability to similar settings. Details of sampling processes and the use of quotes to provide 
insight into participants' thoughts and experiences allows others to evaluate how the findings fit onto other contexts.

\section{FINDINGS}

Analysis of the transcripts revealed themes relating to personal and professional perceptions of death and attitudes to offering choice. The perceived benefits and challenges of offering choice and the education and support required to do this effectively were clearly expressed by participants.

\section{Perceptions of death}

All participants accepted the traditional concept of death where there is no pulse or breathing. Participants acknowledged that people associate being dead with the heart stopping, with one nurse relating the thoughts of her own family stating:

'They would be thinking that her heart is beating, so how can she be dead?' (P10)

When reflecting on BSD the majority $(n=14)$ of participants had difficulty in describing when they would consider death to have taken place. Participants perceived BSD as signifying the point of no return:

'...it controls all of the person's faculties... without that there is no return' (P6)

Other participants talked about the dying process:

'...when the ventilator is switched off...cellular death will occur in the rest of the body as well' (P8)

The difficulty in accepting the concept of BSD was attributed to the physical signs of life that are present and the cultural context. Personal experience of observing BSD tests helped participants to come to terms with the concept: 
'....initially it was difficult... what made it easier for me to accept was my experience...I could see when the BSTs were done that there's no way that the patient was living' (P1).

Participants acknowledged that despite their professional experience, it can be difficult at a personal level to accept a diagnosis of BSD:

'...even though, I know the first set, is the legal time of death, emotionally, I still waited for them to come back after having done the second set before I could accept...it surprised me' (P16)

Participants were not convinced that families understood the concept:

'...the hardest thing for relatives is coming...back...in when l've told them they're dead, and then they look up at the screen...there's definitely a disconnect at that point...I talk to them about that...I explain what the diagnosis of BSD is and I tell them that it's medically and legally death...I think the majority of people are happy to accept doctors explanations' (P2).

'...it's still an alien concept to the vast majority of people...sometimes maybe they pretend that they understand the patient is dead, but more, they understand that the patient is...never going to survive...I think they just accept what we say as opposed to understanding it themselves' (P17).

\section{Offering choice}

All participants accepted choice is not routinely offered to families but the majority of participants, nurses $(n=10)$ more than doctors $(n=3)$, did favour offering choice:

'...I feel that it's their right, it's their son, daughter, husband' (P5).

Others suggested the provision of choice might not be applicable to everybody and depended on other factors: 
'Should all families be offered that whether they have got an acceptance or not, I don't think so...if they understand and they accept it...and they relayed that back to me, I don't see any advantage in bringing them in for the procedure' (P15).

A few consultants $(n=4)$ initially opposed to offering families the choice, stated they would facilitate the presence of families if the relative asked to be present, however, one participant added:

'I must say that I would be...trying very hard to dissuade them from it' (P7).

In addition to these views, subthemes emerged that clarified the reasons for the variety of attitudes to offering choice.

\section{Less traumatic than CPR}

Nine participants felt the choice to be present at BSD testing was similar to the choice given to families during CPR:

'I think generally...CPR would actually be more traumatic...it is much more sudden...it could potentially be more gruesome. With brainstem testing...everything is quiet...it's a fairly civilised sort of thing' (P17).

\section{A medical examination}

Three participants could not appreciate why relatives may wish to be present for BSD tests when they never asked to be present during other interventions. One participant did not think the current approach should change:

'...it's a medical way of checking things...I don't think it's fair on the patient...the family...the physicians who are conducting it because it is 
stressful for every individual involved and ethically, logically, it does make sense the way it's done now...I don't see why it should be changed' (P20).

When asked why it was not a choice given to families more often, one consultant replied:

'I think it's because it's seen as a clinical examination and something that involves us and doesn't involve the families when in actual fact, it's the death of the individual and it does involve the family' (P16).

\section{Organisational culture}

Families were facilitated at BSD testing if they asked or insisted on being present. Three nurses described experiences where they wanted to offer the choice to be present but felt unable to do so:

'...she keeps telling...see you can see his heart beating and he is not really dead, he's not gone...it was very difficult for her... I have always thought...if she was present when we do this...it did cross my mind but of course that wasn't the way it's done...here' (P10).

One consultant also felt inhibited by this culture:

'...like I said, if it was more...socially acceptable...I would probably broach that much more readily...I wouldn't necessarily offer...if it's not the done thing...you say, oh come in and then....sister says...ah that's not the done thing...you can't do it and...that complicates...an already complicated grieving process' (P17).

This article is protected by copyright. All rights reserved. 


\section{Medical paternalism}

Medical paternalism emerged as another reason for not offering families a choice to be present at BSD testing:

'...It's enough stress for relatives...this whole choice and decisionmaking...can they be present...yes...but I will not put that into their mind when I don't think it's necessary...I don't think it adds anything to alleviate their sorrow or their sadness for later on in their life' (P20).

When asked if relatives who were determined to be present and would not be dissuaded still had a choice to be there, one participant responded:

'No, ...l'm not treating them, I'm treating their relative...we want to meet them half way in the journey and we don't want to isolate people but...sometimes we go over the top...too PC [politically correct] and we give everyone the choice for anything and everything...sometimes that choice isn't good for you...sometimes we need to be a little bit paternalistic and sort of say no, that's not right' (P7).

\section{Trust}

It was suggested if the healthcare team established trust the family would be less likely to want to be present:

'...some families would say, no, we are happy with what you do and we trust that way' (P10)

Another participant who had the experience of family presence shared a different perspective:

'...I assumed...in the outset that...he wanted to see as proof but actually...when he was in for the tests, it became more apparent...he just 
wanted to see what was happening at the time and I firmly believe that he wanted to be with his brother...during those tests' (P8).

\section{Perceived benefits and challenges}

Although three consultants felt there was no benefit to offering families a choice to be present, the majority of participants $(n=17)$ felt the main benefits for relatives may be acceptance, closure and a better understanding. It was proposed if families witnessed the tests they would:

'...see for themselves what the test showed rather than someone just telling them' (P4).

Although four participants had no concerns regarding offering families a choice to be present at BSD testing, the majority $(n=16)$ of participants expressed some reservations. There was a worry that observation of the tests may be too traumatic for families:

'...for their loved one to see those procedures taking place....could...be quite disturbing for them...so I wouldn't want them associating their loved one with these tests taking place and witnessing it' (P6).

Two nurses and two consultants expressed concern that families may feel obliged to be there by misunderstanding the choice. Some $(n=6)$ participants suggested these issues could be overcome by planning how to introduce choice to relatives and having a dedicated person there to look after them. 
Five participants suggested the presence of families could result in disruption as a result of having to explain procedures or distraction by being aware of others providing explanations of what was happening. The need for relatives to have a clear understanding of the BSD tests was emphasised. Consultants suggested this lack of understanding might result in them being surprised at how crude BSD tests actually are:

'I wonder do people think there is more to it...I wonder in this day and age do they think, they're going to do something very scientific' (P8).

Another consultant was concerned about the time required to bring families to an understanding of how the tests would be carried out. Nurses acknowledged there is often time to prepare family for witnessing testing stating:

'...it's not usually a quick thing...we need to make sure sedation has been off for so long...so there would be time to discuss it with the medical staff and involve the family' (P4).

\section{Education and Support}

Increased knowledge and communication skills training were identified as key requirements to enable healthcare professionals to facilitate family presence. Doctors felt minimal education or support was needed if it was agreed that choice should be offered. Nurses felt they needed more knowledge to effectively and confidently answer questions asked by family members. It was suggested an information aid that would prompt explanation for relatives should be developed. Some participants felt: '...teaching people to be open about allowing families in at difficult times...' (P18) would be the biggest challenge. 
Communication was identified by all participants as a key skill needed to support families to make informed decisions about witnessing BSD testing. Some participants felt study days, workshops and simulations would increase their understanding. This would allow staff to experiment with words and receive feedback, developing their confidence to interact with relatives in a compassionate way:

'...sometimes I am so worried about the words I use...I've seen other people dealing with situations like that...use beautiful words...I would love to know if they have any training on how to use those lovely words' (P11).

Participants suggested measures healthcare professionals would need to consider putting in place to facilitate family presence, before, during and after witnessing BSD testing.

The choice to be present should be offered at the initial consultation when the need for BSD testing was introduced. Some participants $(n=7)$ felt this verbal invitation could be supported by an information leaflet that would explain the concept of BSD and offer the choice in a way that welcomes them but does not oblige them to be there.

Almost all $(n=19)$ of the participants acknowledged that time for decision-making and preparation prior to testing was crucial to reduce the risk of psychological and emotional harm for families. Although one participant was not convinced people would be in a position to make a choice, another suggested: 
'...people always want choice, that's human nature, you don't want to feel you've been left out of that or that you are not involved in the decision-making process' (P13).

Preparation of the environment prior to testing was mentioned by ten participants.

Creating a calm environment with as much privacy as possible was important:

'...a nice environment where it's a tidy bed space for them...and there would be chairs...a glass of water...whatever they need to keep them comfortable and...safe' (P3).

During the tests support for the family member and freedom to leave were identified as being important. It was recognised staff needed an awareness of cultural and religious differences in order to offer effective support. Several participants $(n=13)$ felt a member of staff should be allocated to support the family and if the family wished their spiritual advisor to be present this should be facilitated. One participant felt strongly that the Specialist Nurse for Organ Donation (SNOD) should not be involved at this stage:

'You would need to have...someone who is not part of the transplant team with them... I do strongly believe the SNODs should not be near this' (P19).

All participants felt nurses who had established rapport with the families would be the best person to provide support, suggesting the role would include explanation regarding the tests and provision of emotional support as required. One participant felt relatives should have access to touching the patient: 
'...it's really just trying to create an atmosphere that is very conducive to them feeling...that they can participate in it in such a way that they have access to touching their relative' (P9).

Ten participants recognised family members should have the freedom to leave:

‘Just because you asked to be there, doesn't mean you need to be there to the conclusion....if you decide I can't take this, I need to get out...you get out...your person who is with you is immediately available to leave with you' (P8).

It was felt family members should be given the opportunity, as a form of debrief after the tests, to seek clarification on any issues they identified prior to, during or after the testing.

\section{DISCUSSION}

This study aimed to explore the views and perceptions of healthcare professionals on offering families the choice to be present during BSD testing. The findings include some important issues that challenged experienced professionals. The loss of a loved one is a universal experience, shaded with cultural beliefs and values and an understanding of factors that influence the provision of effective end-of-life care and support for families is crucial.

Although BSD was viewed as equivalent to cardiac death, cognitive dissonance was identified among participants. While accepting BSD on a professional level, many participants acknowledged that they would struggle personally to accept the loss of a relative through $\mathrm{BSD}$. This supports research suggesting inconsistency in 
acceptance of BSD as death among healthcare professionals (Ronayne 2009). This ambivalence could be attributed to gaps in understanding, but has the potential to influence the confidence with which communication and care is provided to families during BSD testing, particularly when it is regularly assumed that families accept the explanations offered without questioning.

Whilst the majority of participants felt families should be offered choice neither of the ICUs involved in this study routinely did so; family presence was only facilitated if families persisted in asking. The ad hoc nature of this practice begs the question about the subsequent quality of the preparation and experience. In not offering choice, practice is not reflecting international evidence reporting families' desire to be given the option of witnessing the tests. Conversely, those who accepted were grateful for the experience of being present (Omrod et al. 2005, Twail et al. 2014). Participant responses demonstrated that the right of families to be present conflicted with the routines of care and illustrated the influence of the professional and environmental context and culture.

The participants' thinking processes could be traced clearly through the interviews. Some expressed initial negative responses to offering choice to families but then proceeded to respond to further questions in a way that evidenced they were exploring their personal beliefs and values. These were then applied when exploring how choice might work in practice before reaching a consensus that, if preparation was in place, choice could be possible. This demonstrates the nature of the topic to polarise views, but also that consideration can challenge the initial response to the idea of offering choice. The subthemes demonstrated that rationalisation process. 
Participants were able to make comparisons to family presence during CPR and as a result bring themselves to see BSD testing as a planned event that could be undertaken in a dignified manner. The readiness to accept the feasibility of family presence during BSD testing in the context of the evidence surrounding family presence during CPR is encouraging and provides a clear starting point to initiate change in accepted, yet sometimes controversial, ICU practice.

Other participants could not understand why families would want to be present for what they viewed as a medical examination and the emergence of medical paternalism was evident in some responses. By failing to involve families at this important time, healthcare professionals may not be meeting the families' needs for person-centred care. Participants suggested healthcare professionals should be more courageous in communicating with families if choice is to become a reality. A proactive approach is needed as participants accepted it is unlikely family members would ask to be present. Dean and Booth (2009) reported 27 hospitals did not allow relatives to witness BSD testing because families never asked. Participants felt while in hospital, families might not think about asking to be present but it may be something they ponder at home.

Some doctors suggested family members would only want to be present if they mistrusted the diagnosis. Ormrod et al. (2005) suggests a culture of greater openness and family involvement may foster a climate of greater trust. Offering families a choice would demonstrate transparency and allow families to achieve an understanding that all that could be done was being done (Poles \& Bousso 2011). The culture in the units was seen as a major barrier to doctors and nurses offering 
families the choice to be present at BSD testing. Some participants agreed families should be offered the choice, but felt inhibited in making this happen. As a positive attitude is not sufficient for a specific behaviour to be demonstrated (Kim et al. 2006), a change in culture within ICUs is needed if families are to be afforded the right to choose (Keith-Lucas 2010, Duss-Otterström 2011). It is apparent that shared decision-making and power is needed to develop supportive organisational cultures that will foster safe innovation and risk-taking, an integral aspect of effective personcentred practice (McCormack \& McCance 2010).

Perceived benefits for families who chose to be present were identified as improved understanding of the process that could lead to a sense of acceptance and closure during the grieving process. Further research needs to be carried out to ascertain if this could be achieved.

Concern was expressed about how families would respond to the reality of watching testing. There have been reports that trauma may be caused by witnessing tests (Frid et al. 2007) but research suggests staff have no idea how difficult the experience of waiting is for families who are suspended between feelings of fear and hope (Ormrod et al. 2005). It is naïve to assume that excluding family members from testing means trauma will be prevented. It has been reported that subjects randomised to be present at testing had lower Impact of Event Scale scores than those randomised to be absent (Twail et al. 2014). A secondary concern was the potential for the presence of family members to disrupt or distract during procedures. Similar concerns have been reported as reasons for not offering families a choice to 
be present at BSD testing but these have not been supported by evidence (Dean \& Booth 2009, Ronayne 2009, Twail et al. 2014).

Care needs to be taken to ensure families do not feel obliged to be present. Concerns were expressed that family members would not be capable of making a rational choice. Participants felt these issues could be overcome with careful wording of the offer of choice and the allocation of a dedicated person to care for the family. This would contribute to developing the readiness necessary for volitional action (Ryan \& Deci 2006). This family-centred approach supports choice in informed decision-making, contributes to empowerment and is consistent with a broader trend within healthcare towards a climate of involvement (Ormrod et al. 2005, Twail et al. 2014;).

Of interest was the concern that BSD testing would appear a crude procedure in the context of the technological support used in ICUs but evidence suggests families can understand the testing process (Ormrod et al. 2005, Kompanje et al. 2012). In a study of thirty-eight participants randomly selected to be present at BSD testing, thirty-six (94.7\%) reported that being present helped them understand BSD with thirty-two (84\%) willing to recommend family presence to others (Twail et al. 2014). The time needed to bring families to the point of understanding was a concern for one participant. Consultants recognised that achieving this will not come without resource challenges; however, nurses who were already providing direct care to the family at the bedside appeared to see this as an extension of their existing role. 
Establishing the education needs of healthcare professionals in ICUs is necessary if families are to be involved and supported effectively. Nurses appeared more aware of the implications of offering support to families in terms of increasing their own knowledge and confidence. This is reflected in the findings of Collins (2005) where although $61 \%$ of nurses felt they could adequately explain BSD to relatives, $26 \%$ felt they could not and a further $13 \%$ were unsure with knowledge deficits being predominantly found amongst junior nurses.

The importance of effective communication between healthcare professionals and families cannot be underestimated as it plays a major role in minimising family confusion and supporting understanding and acceptance of BSD (Twail et al. 2014). Talking to families, listening to their anxieties and providing an opportunity to voice fears enables healthcare professionals to include families in an open manner (Fridh et al. 2007, Poles \& Bousso 2011).

A significant degree of preparation is necessary to ensure those who choose to be present come to no further emotional harm. During this phase of the interview it was evident that participants were imagining how this could be managed in practice. The findings indicate choice should be offered to families during the initial consultation when the need for BSD testing is introduced. As relatives may not fully appreciate all the information being given at this time, additional information leaflets and resources about BSD testing and choosing to be present may aid communication and decision-making (Ronayne 2009). It was recognised that families needed time to consider the choice with further preparation for those who choose to be present to ensure they have adequate knowledge of the procedures to be performed. 
Preparation of the environment prior to the procedure was highlighted as essential to create a peaceful atmosphere. Support for family members and the freedom to leave at any point during testing were crucial to facilitating the presence of families. To support families, participants suggested doctors and nurses needed to have an awareness of the cultural, religious and ethical issues surrounding acceptance of BSD (Bagheri 2006). It is vital the family's spiritual practices are respected and that families have the support needed to face the death of their loved one (Poles \& Busso 2011). This emphasises the key role of the supporting nurse in providing emotional support and information during testing and the opportunity to ask questions following testing. It was clear that participants were moving towards an appreciation of the need for engagement to create a therapeutic environment for supportive familyfocussed care.

\section{Limitations}

The qualitative design of this study involving a small sample in two critical care units in a region of the United Kingdom may limit the national or international generalizability of findings. Despite this, in accordance with the principles of qualitative enquiry, the relevance of these findings for other healthcare professionals can be established through dissemination, reflection and analysis of their own experiences and practice contexts.

It important to bear in mind those healthcare professionals and families from different cultures and faiths, and also no faith, may hold different perspectives. The cultural and religious background of participants was not explored in this study and this could have influenced the results. 


\section{CONCLUSION}

This study suggests healthcare professionals have different perceptions of death when reflecting on the concept of BSD. Despite the choice to be present at BSD testing not being routinely offered to families, the majority of participants felt this should be considered in practice. While participants suggested offering choice to families had a number of perceived benefits, they also expressed a number of concerns that would need to be considered and managed if this is to become common practice. Key educational and support needs have been identified to ensure healthcare professionals have the knowledge and skills to support families at this critical time. Despite international variation in health care systems, local practices and the role of health care professionals in critical care, the role of providing care and support, not only to the patient but also to families, is universally represented in an understanding of person-centred practice, particularly so at the end-of-life in the context of BSD.

\section{RELEVANCE TO CLINICAL PRACTICE}

The majority of healthcare professionals interviewed would support offering families a choice to be present at BSD testing. This view is consistent with a small but growing body of international evidence from across North America, Europe and East Asia advocating for the presence of families at BSD testing. It is hoped these findings will initiate a change in ICU practice, so that all families will be given the choice of being present during BSD testing. Equipping staff with the knowledge, skills and confidence to competently facilitate families will be important if this is to become a reality. This type of proactive approach will require a shift in culture within most ICUs if healthcare professionals are to play a pivotal role in bringing about this 
significant change to current practice. This may be achieved by further research into the culture and constraints in critical care settings and the attitudes of professionals providing care. It is important to explore the need, whether expressed currently or not, to offer choice taking into consideration differing culture, belief and value contexts. The development of guidelines that take into account the cultural and professional variations yet provide a comparable standard of end-of-life care is crucial for families.

\section{0 words}

\section{REFERENCES}

Academy of Medical Royal Colleges (AMORC) (2008) A Code of Practice for the Diagnosis and Confirmation of Death. PPG Design and Print Ltd, London

Bagheri A (2006) Individual choice in the definition of death. Journal of Medical Ethics 33, 146-149. http://dx.doi.org/10.1136/jme.2006.016014

Bell MDD \& Murphy PG (2004) Brainstem death testing in the UK - time for reappraisal?

British Journal of Anaesthesia 92, 633-640. http://dx.doi.org/10.1093/bja/aeh108

Bernat, JL (2009) Contemporary controversies in the definition of death. Progress in Brain Research 177, 21-31. http://dx.doi.org/10.1016/S0079-6123(09)17703-8

Canadian Blood Services \& World Health Organisatipon (WHO) (2012) International guidelines for the determination of death - Phase 1. Montreal Forum Report. Canadian Blood Services, Ontario. Available at: http://www.who.int/patientsafety/montreal-forumreport.pdf (accessed 24 February 2016).

Collins TJ (2005) Organ and tissue donation: a survey of nurse's knowledge and educational needs in an adult ITU. Intensive and Critical Care Nursing 21, 226-231.

http://dx.doi.org/10.1016/j.iccn.2004.10.006

Dean PA \& Booth MG (2009) Survey of family-witnessed brain stem death testing in intensive care units. The Intensive Care Society 10, 282-284.

http://dx.doi.org/10.1177/175114370901000414

Doran M (2004) The presence of family during brain stem death testing. Intensive and Critical Care Nursing 20,:32-37. http://dx.doi.org/10.1016/j.iccn.2003.10.003

This article is protected by copyright. All rights reserved. 
Duss-Otterström FG (2011). Freedom of will and the value of choice. Social Theory and Practice 37(2), 256-284. http://dx.doi.org/10.5840/soctheorpract201137215

Flick U (2014). An introduction to Qualitative Research. 5th edn, London: Sage

Frid I, Haljamäe H, Ōhlén J, Bergbom I (2007) Brain death: close relatives' use of imagery as a descriptor of experience. Journal of Advanced Nursing 58, 63-71.

http://dx.doi.org/10.1111/j.1365-2648.2007.04208.x

Fridh I. Forsberg A. and Bergbom I. (2007). Family presence and environmental factors at the time of a patient's death in an ICU. Acta Anaesthesiologica Scandinavica 51, 395-401. http://dx.doi.org/10.1111/j.1399-6576.2006.01250.x

Fullbrook P. Albarran JW. \& Latour JM. (2005) A European survey of critical care nurses' attitudes and experiences of having family members present during cardiopulmonary resuscitation. International Journal of Nursing Studies 42, 557-568. http://dx.doi.org/10.1016/j.jnurstu.2004.09.012

Fung OYC, Leung KHK, Chung AC, Chan MKD \& Leung KKG (2008) Knowledge, acceptance and perception toward brainstem death among medical students in Hong Kong: a questionnaire survey on brainstem death. Medical Teacher 30, e125-e130. doi: $10.1080 / 01421590801932236$

Haddow G (2004) Donor and nondonor families' accounts of communication and relations with healthcare professionals. Progress in Transplantation 14, 41-48. http://dx.doi.org/10.7182/prtr.14.1.r3510160u371qj20

Joffe A. (2010). Are recent defences of the Brain Death Concept Adequate? Bioethics 24, 47-53. doi.org/10.1111/j.1467-8519.2008.00709.x

Karakatsanis KG (2008) 'Brain death': Should it be reconsidered? Spinal Cord 46, 396-401. doi.org/10.1038/sj.sc.3102107

Keith-Lucas A (2010) Biblical insights into the helping process. Social Work and Christianity 37, 321-329.

Kim JR. Fisher MJ. \& Elliott D. (2006) Attitudes of intensive care nurses towards brain death and organ transplantation: instrument development and testing. Journal of Advanced Nursing 53, 571-582. doi.org/10.1111/j.1365-2648.2006.03759.x

Kompanje EJO, de Groot YJ, Bakker J \& IJzermans JNM (2012) A National Multicenter Trial on Family Presence During Brain Death Determination: The FABRA Study. Neurocritical Care 17, 301-308. doi.org/10.1007/s12028-011-9636-2

Kubler A, Lipinska-Gediga M, Kedziora J \& Kubler M (2009) Attitudes to Brain Death and Organ Procurement Among University Students and Critical Care Physicians in Poland. Transplantation Proceedings 41, 1473-1476. doi.org/10.1016/j.transproceed.2009.01.109

Leske JS. \& Brasel K. (2010) Effects of Family-Witnessed Resuscitation after Trauma Prior to Hospitalization. Journal of Trauma Nursing 17, 11-18.

doi.org/10.1097/JTN.0b013e3181d915b0

This article is protected by copyright. All rights reserved. 
Leung KKH, Fung COY, Au CC, Chan DMK \& Leung GKK (2009) Knowledge and Attitudes Toward Brain Stem Death Among University Undergraduates. Transplantation Proceedings 41, 1469-1472. doi.org/10.1016/j.transproceed.2008.10.096

Lincoln YS \& Guba EG (1985) Naturalistic Inquiry. London, SAGE

Long T \& Addington-Hall J (2008) What does a diagnosis of brain death mean to family members approached about organ donation?: a review of the literature. Progress in Transplantation 18, 118-125. doi.org/10.7182/prtr.18.2.07707n0107q43781

Maas A, Stocchetti N \& Bullock, R (2008) Moderate and severe brain injury in adults. Lancet Neurology, 7, 728-41. doi:org/10.1016/S1474-4422(08)70164-9.

MacDonald ME, Liben S, Carnevale FA \& Cohen SR (2012). Signs of life and signs of death: brain death and other mixed messages at the end of life. Journal of Child Health Care 12, 92-105. doi.org/10.1177/1367493508088546

Machado C (2010) Diagnosis of brain death. Neurology International 2(e2), 7-13. doi.org/10.4081/ni.2010.e2

McCormack, B and McCance T (2010) Person-centred Nursing: Theory and Practice. Wiley Blackwell, Oxford.

Nathan S \& Greer DM (2006) Brain death. Seminars in Anaesthesia,Perioperative Medicine and Pain 25, 225-231. doi.org/10.1053/j.sane.2006.09.005

Newell, R \& Burnard P (2006) Vital Notes for Nurses: Research for Evidence-Based Practice. Blackwell Publishing, Oxford.

Ormrod JA, Ryder T, Chadwick RJ \& Bonner SM (2005) Experiences of families when a relative is diagnosed brain stem dead: understanding of death, observation of brain stem death testing and attitudes to organ donation. Anaesthesia 60, 1002-1008.

doi.org/10.1111/j.1365-2044.2005.04297.x

Parahoo K (2014. Nursing Research: principles, process and issues. 3rd edn. Palgrave Macmillan, London.

Poles K \& Bousso RS (2011). Dignified Death: Concept development involving nurses and doctors in Pediatric Intensive Care Units. Nursing Ethics 18, 694-709.

doi.org/10.1177/0969733011408043

Reid M (2013) The presence of relatives during brainstem death testing in an intensive care unit. Journal of the Intensive Care Society 14, 324-329.

doi.org/10.1177/175114371301400410

Romanini J, Daly J. (1994). Critical Care Nursing: Australian Perspectives. Sydney: W.B.

Saunders/Baillière Tindall.

Ronayne C (2009) A phenomenological study to understand the experiences of nurses with regard to brainstem death. Intensive and Critical Care Nursing 25: 90-98.

doi.org/10.1016/j.iccn.2008.06.001

This article is protected by copyright. All rights reserved. 
Ryan RM \& Deci EL (2006) Self-regulation and the problem of human autonomy: does psychology need choice, self-Determination and will? Journal of Personality $74,1557-1586$. doi.org/10.1111/j.1467-6494.2006.00420.x

Shewmon A (2009) Brain death: can it be resuscitated? Hastings Centre Report 39, 18-24. DOI: $10.1353 /$ hcr.0.0122

Twail I, Brown LH, Comfort D, Crandall CS, West SD, Rollstin AD, Dettmer TS, Malkoff MD \& Marinaro J (2014) Family presence during brain death evaluation: a randomised controlled trial. Critical Care Medicine 42, 934-942. doi.org/10.1097/CCM.0000000000000102

\section{TABLE 1 - BRAIN STEM REFLEXES IN THE PATIENT WHO IS ‘BRAIN DEAD’}

\begin{tabular}{|l|l|l|}
\hline $\begin{array}{l}\text { Brain Stem Reflexes } \\
\text { Assessed }\end{array}$ & Findings in Brain Death & $\begin{array}{l}\text { Cranial Nerves } \\
\text { Tested }\end{array}$ \\
\hline Pupillary reflexes & $\begin{array}{l}\text { Absent response to bright light (pupils } \\
\text { at midpoint with respect to dilatation } \\
4-6 \mathrm{~mm})\end{array}$ & II and III \\
\hline $\begin{array}{l}\text { Facial sensory and } \\
\text { motor responses }\end{array}$ & $\begin{array}{l}\text { Absence of grimacing or eye opening } \\
\text { in response to pain, e.g. deep } \\
\text { pressure on temporomandibular joints }\end{array}$ & $\begin{array}{l}\text { Afferent V and } \\
\text { efferent VII }\end{array}$ \\
\hline Corneal reflexes & $\begin{array}{l}\text { Absence of grimace/pain response } \\
\text { when edge of cornea is touched. }\end{array}$ & V and VII \\
\hline Oculo-cephalic reflex & $\begin{array}{l}\text { Absence of deviation of eyes to } \\
\text { opposite side following rapid head } \\
\text { turning 90 (doll's eye phenomenon) }\end{array}$ & III, VI and VIII \\
\hline Oculo-vestibular reflex & $\begin{array}{l}\text { Absence of response (deviation of } \\
\text { eyes towards side of cold stimulus } \\
\text { provided by introduction of ice water) }\end{array}$ & III, VI and VIII \\
\hline Pharyngeal (gag) reflex & $\begin{array}{l}\text { Absent - elicited by stimulating rear } \\
\text { of pharynx with tongue depressor }\end{array}$ & $\begin{array}{l}\text { IX and X (Caloric } \\
\text { test) }\end{array}$ \\
\hline Tracheal (cough) reflex & $\begin{array}{l}\text { Absent - elicited by inserting a } \\
\text { suction catheter deep into the trachea }\end{array}$ & IX and X \\
\hline
\end{tabular}

(Romanini \& Daly, 1994)

This article is protected by copyright. All rights reserved. 
Table 2

\begin{tabular}{|c|l|l|c|}
\hline $\begin{array}{l}\text { Participant } \\
\text { Identification } \\
\text { No: }\end{array}$ & GENDER & PROFESSION & $\begin{array}{l}\text { YEARS OF } \\
\text { EXPERIENCE }\end{array}$ \\
\hline 1 & Female & Nurse (Band 5) & 7 \\
\hline 2 & Male & Consultant & 11 \\
\hline 3 & Female & Nurse (Band 6) & 14 \\
\hline 4 & Female & Nurse (Band 5) & 6 \\
\hline 5 & Female & Nurse (Band 6) & $>20$ \\
\hline 6 & Male & Nurse (Band 6) & 5 \\
\hline 7 & Male & Consultant & 19 \\
\hline 8 & Female & Consultant & 12 \\
\hline 9 & Female & Nurse (Band 7) & $>20$ \\
\hline 10 & Female & Nurse (Band 6) & 15 \\
\hline 11 & Female & Nurse (Band 6) & 8.5 \\
\hline 12 & Female & Nurse (Band 6) & 15 \\
\hline 13 & Male & Consultant & 10 \\
\hline 14 & Male & Nurse (Band 6) & 12 \\
\hline 15 & Male & Consultant & 12 \\
\hline 16 & Female & Consultant & 20 \\
\hline 17 & Male & Consultant & 13 \\
\hline 18 & Female & Consultant & 15 \\
\hline 19 & Female & ST7 Anaesthetics & 10 \\
\hline 20 & Male & Consultant & 14 \\
\hline & & & \\
\hline
\end{tabular}

\section{Table 3}

\section{Semi-structured Interview Protocol (including possible probes*)}

Introduction - Introduce self and establish a rapport with the participant. Gather generic information, i.e. name, grade, years of experience in ICU, etc. Outline the background for the project and purpose of the interview and thank them for taking part.

Q1 - When would you consider someone to be dead?

Do you feel there is any difference between your personal and professional views? If yes - can you explain this to me?

If no - Go to Q2

Q2 - When someone is diagnosed as brainstem dead, do you accept that they are dead?

If yes, do you accept that death has occurred at all levels of the organism? If no - can you tell me why do you not accept that these patients are dead?

Q3 - Do you think that family members should be given the choice to be/not to be present at brainstem death testing?

If yes - Have you ever invited/allowed on request, relatives to witness BSD testing? If no - Why do you think that family members should not be given the choice to be/or not to be present at brainstem death testing?

This article is protected by copyright. All rights reserved. 
Q4 - In your own words can you tell me what you think/found the benefits to be if/when family members were given the choice to be present at brainstem death testing?

Q 5 - Have you any concerns about giving families the choice to be/or not to be present?

If yes - What are your concerns with giving family members a choice to be/not to be present?

If no - would you have any concerns/experienced any problems if a family member chooses to be/was present? (If yes, what are these concerns/experiences; if no go to Q6?).

Q6 - What education or support do you feel you/staff would need to enable you to facilitate the presence of family members at brainstem death testing?

Q7 - What measures do you think healthcare professionals need to put in place to meet the needs of family members who choose to be present?

Closure - Is there anything else you would like to add? Thank the individual for their participation and do not leave any anxieties demonstrated unresolved; offer contact details of Trust bereavement counsellor if required.

*Please note that as this is a semi-structured interview probes may alter depending on the flow of the conversation and in response to cues or answers given. However, the researcher will ensure that all key questions are addressed when interviewing each participant.

This article is protected by copyright. All rights reserved. 